Article

\title{
Initial Results of the Precise Orbit Determination for the New-Generation BeiDou Satellites (BeiDou-3) Based on the iGMAS Network
}

\author{
Bingfeng Tan ${ }^{1,2, *}$, Yunbin Yuan ${ }^{1, *}$, Mingyue Wen ${ }^{3}$, Yafei Ning ${ }^{1,2}$ and Xifeng Liu ${ }^{1,2}$ \\ 1 State Key Laboratory of Geodesy and Earth's Dynamics, Institute of Geodesy and Geophysics, \\ Chinese Academy of Sciences, Wuhan 430077, China; yafeining@whigg.ac.cn (Y.N.); lxf@whigg.ac.cn (X.L.) \\ 2 University of Chinese Academy of Sciences, No. 19A Yuquan Road, Beijing 100049, China \\ 3 The Primary School of Vanke Golden City Attached to Central China Normal University, \\ Wuhan 430065, China; mingyue_wen@126.com \\ * Correspondence: bingfengtan@whigg.ac.cn (B.T.); yybgps@asch.whigg.ac.cn (Y.Y.); \\ Tel.: +86-186-0271-9861 (B.T.)
}

Academic Editors: Zhao-Liang Li, Jose A. Sobrino, Chao Ren and Wolfgang Kainz Received: 26 August 2016; Accepted: 23 October 2016; Published: 27 October 2016

\begin{abstract}
By August 2016, 5 new-generation BeiDou satellites (BeiDou-3) have successfully been launched. The observations of a very limited number of 9 International GNSS (Global Navigation Satellite System) Monitoring and Assessment Service (iGMAS) stations and 52 Multi-GNSS Experiment (MGEX) stations from 16 July to 14 August 2016 are processed to determine the orbits of BeiDou-3 and BeiDou-2 satellites, respectively. The internal consistency and satellite laser ranging (SLR) validations are conducted for the orbit validation. BeiDou-3 MEO (Medium Earth Orbit) (C33 and C34) have larger root mean square (RMS) values than those BeiDou-3 IGSO (C31 and C32), whereas BeiDou-2 MEO satellites have smaller RMS values than the BeiDou-2 IGSO satellites. Furthermore, BeiDou-3 IGSO and BeiDou-2 satellites have RMS values at identical levels, whereas BeiDou-3 MEO satellites have larger RMS values than the BeiDou-2 MEO satellites. The RMS residuals are approximately $10 \mathrm{~cm}$ in the radial component and approximately $25 \mathrm{~cm}$ in the along component for BeiDou-3 IGSO satellites. For BeiDou-3 MEO satellites, the RMS residuals are approximately $40 \mathrm{~cm}$ in the radial component and approximately $60 \mathrm{~cm}$ in the along component. The SLR validation reports that the orbit radial component can reach an accuracy on the level of 1 decimeter and 4 decimeters for BeiDou-3 IGSO and MEO, respectively.
\end{abstract}

Keywords: BeiDou; precise orbit determination; overlap comparison; satellite laser ranging

\section{Introduction}

China is constructing the BeiDou Navigation Satellite System (BDS), which is an important constellation that contributes to the Global Navigation Satellite System (GNSS) and Geodesy community [1]. The deployment of BDS is divided into two phases: the regional system and the global system. Following the completion of the first deployment phase, which involved a constellation of five satellites in geostationary orbit (GEO), five in inclined geosynchronous orbit (IGSO), and four in medium earth orbit (MEO), BDS has been officially providing continuous passive positioning, navigation, and timing services for the Asia-Pacific area since 27 December 2012. In 10 February 2015, according to the news from the Ministry of Transportation, in the 94th meeting of IMO (International Maritime Organization) Maritime Safety Committee, the Navigation Safety Circular of BeiDou Navigation Satellite System was officially approved. As of August 2016, there are 14 BeiDou-2 satellites in operation: five GEO satellites, six IGSO satellites, and three MEO satellites. On 30 March 2015, China's first New-Generation (BeiDou-3) Navigation satellite was 
successfully launched, which signaled the beginning of BDS's expansion from regional to worldwide coverage. By August 2016, five BeiDou-3 satellites, each of which has a new navigation signal system, inter-satellite links, and other test features, have been launched, which brings the satellite navigation system closer to completion. Four BeiDou-3 satellites are now in operation. The status of the BeiDou Navigation Satellite System (updated as of August 2016) is summarized in Table 1 [2].

Table 1. BeiDou navigation satellite system status (as of August 2016).

\begin{tabular}{|c|c|c|c|c|c|}
\hline \multicolumn{6}{|c|}{ Beidou-2 } \\
\hline Satellite & PRN & SVN & Type & Notes & Launch Date \\
\hline G01 & $\mathrm{C} 01$ & $\mathrm{C} 003$ & GEO & $140.0^{\circ} \mathrm{E}$ & 17 January 2010 \\
\hline G02 & $\mathrm{C} 02$ & $\mathrm{C} 002$ & GEO & Not in operation & 15 April 2009 \\
\hline G03 & $\mathrm{C} 03$ & $\mathrm{C} 004$ & GEO & $84.0^{\circ} \mathrm{E}$ & 2 January 2010 \\
\hline G04 & $\mathrm{C} 04$ & C006 & GEO & $160.0^{\circ} \mathrm{E}$ & 1 November 2011 \\
\hline G05 & $\mathrm{C} 05$ & C011 & GEO & $58.75^{\circ} \mathrm{E}$ & 25 February 2012 \\
\hline G06 & $\mathrm{C} 02$ & C016 & GEO & $110.5^{\circ} \mathrm{E}$ & 25 October 2012 \\
\hline G07 & $\mathrm{C} 17$ & C017 & GEO & In orbit test & 12 June 2016 \\
\hline $\mathrm{I} 01$ & $\mathrm{C} 06$ & C005 & IGSO & $122^{\circ} \mathrm{E}$ & 1 August 2010 \\
\hline I02 & $\mathrm{C} 07$ & $\mathrm{C} 007$ & IGSO & $119^{\circ} \mathrm{E}$ & 18 December 2010 \\
\hline $\mathrm{I} 03$ & $\mathrm{C} 08$ & C008 & IGSO & $120^{\circ} \mathrm{E}$ & 10 April 2011 \\
\hline I04 & $\mathrm{C} 09$ & $\mathrm{C} 009$ & IGSO & $96.5^{\circ} \mathrm{E}$ & 27 July 2011 \\
\hline I05 & $\mathrm{C} 10$ & $\mathrm{C} 010$ & IGSO & $92.5^{\circ} \mathrm{E}$ & 2 December 2011 \\
\hline I06 & $\mathrm{C} 15$ & C017 & IGSO & $95^{\circ} \mathrm{E}$ & 29 March 2016 \\
\hline M01 & $\mathrm{C} 30$ & C001 & MEO & Not in operation & 4 April 2007 \\
\hline M03 & $\mathrm{C} 11$ & $\mathrm{C} 012$ & MEO & & 30 April 2012 \\
\hline M04 & $\mathrm{C} 12$ & $\mathrm{C} 013$ & MEO & & 30 April 2012 \\
\hline M05 & $\mathrm{C} 13$ & C014 & MEO & Not in operation & 18 September 2012 \\
\hline M06 & $\mathrm{C} 14$ & $\mathrm{C} 015$ & MEO & & 18 September 2012 \\
\hline \multicolumn{6}{|c|}{ Beidou-3 } \\
\hline Satellite & PRN & SVN & Type & Notes & Launch Date \\
\hline I1-S & C31 & C101 & IGSO & & 30 March 2015 \\
\hline M1-S & $\mathrm{C} 33$ & C102 & $\mathrm{MEO}$ & & 25 July 2015 \\
\hline M2-S & $\mathrm{C} 34$ & C103 & MEO & & 25 July 2015 \\
\hline I2-S & $\mathrm{C} 32$ & C104 & IGSO & & 29 September 2015 \\
\hline M3-S & $\mathrm{C} 35$ & $\mathrm{C} 105$ & MEO & In orbit test & 1 February 2016 \\
\hline
\end{tabular}

With the increasing quality requirements for civilian and scientific applications based on the emerging global BDS [3-11], achieving a precise orbit determination (POD) for the global BDS constellation has become one of the most challenging issues for the Global Navigation Satellite System (GNSS) community. Several studies have been performed on the POD of BeiDou-2 satellites. Ge et al. [12] presented their results of BeiDou-2 satellites POD using three day arcs and nine solar radiation pressure (SRP) parameters of the Empirical CODE Orbit Model (ECOM) with a regional tracking network. The 3D orbit overlap comparison of GEO and IGSO is $3.3 \mathrm{~m}$ and $0.5 \mathrm{~m}$ in root mean square (RMS), respectively. Montenbruck et al. [13] reported the initial orbit and clock assessment of the regional BDS navigation satellite system, and the 3D orbit overlap comparison is 1-20 $\mathrm{m}$ in RMS. Steigenberger et al. [14] demonstrated several solutions of ECOM parameters for BeiDou non-GEO satellites, and only one ECOM SRP parameter in the direction of the Sun was estimated for BeiDou GEO satellites. The orbit consistency was on a 1-2 decimeter level for the IGSO satellites and on a several-decimeter level for the GEO satellites. Zhao et al. [15] introduced an additional constant acceleration in the along direction to compensate for the insufficiency of the ECOM model for GEO satellites, and the five-parameter ECOM SRP model was used. The 3D orbit overlap comparison accuracy was approximately $1.8 \mathrm{~m}$ for GEO and $0.3 \mathrm{~m}$ for IGSO and MEO satellites. The satellite laser ranging (SLR) residuals were approximately $0.7 \mathrm{~m}$ for GEO C01 and $0.1 \mathrm{~m}$ for IGSO C08. Lou et al. [16] engaged the additional constant acceleration in the along direction for GEO satellites and five-parameter ECOM SRP model for non-GEO satellites in their study. The orbit overlap comparison 
accuracy was approximately $20 \mathrm{~cm}$ and several meters for MEO/IGSO and GEO satellites in RMS, respectively. The SLR residuals were better than $10 \mathrm{~cm}$ for MEO/IGSO satellites and several decimeters for GEO satellites.

Precise orbits are a basic requirement needed to expand the global scientific application for the BDS global system, but there are difficulties and limitations in the precise orbit determination of BeiDou-3 satellites. Compared to BeiDou-2 satellites, there are fewer and worse distributed tracking stations. Meanwhile, the optimal dynamic model for BeiDou-3 satellite POD, particularly the SRP model, must be further studied. In this study, we aim to precisely determine the orbit of BeiDou-3 satellites based on a tracking network operated by the International GNSS Monitoring and Assessment Service (iGMAS) in China and investigate the achievable accuracy. The paper is organized as follows: in Section 2, the data collection for BeiDou-3 satellites is introduced. In Section 3, the methods and strategies for BeiDou-3 satellite POD are described, and a POD experiment is conducted. The results of the orbit overlap comparison and SLR validation are presented in Section 4. Finally, some conclusions and discussion are provided in Section 5 .

\section{Data Collection for BeiDou-3 Satellites POD}

The BeiDou-3 satellites retain the navigation-signal-transmitting modulation system in deployment phase 1 (i.e., $1561.098 \mathrm{MHz}$ (B1), $1207.140 \mathrm{MHz}$ (B2), and $1268.520 \mathrm{MHz}$ (B3)). Furthermore, BeiDou-3 satellites will include the migration of its civil BeiDou B1 signal from $1561.098 \mathrm{MHz}$ to a frequency centered at $1575.42 \mathrm{MHz}$, which is identical to the GPS L1 and Galileo E1 civil signals, and its transformation from a quadrature phase shift keying (QPSK) modulation to a multiplexed binary offset carrier (MBOC) modulation similar to the future GPS L1C and Galileo's E1 [17]. Two frequencies of B2 (1176.45 (B2a) and 1207.14 (B2b)) and two frequencies of B3 (1278.75 (B3c) and 1268.52 (B3c)) will be candidates for the migration of civil BeiDou B2 and B3 signals. Because the new signals of BeiDou-3 satellites remain in the internal test stage, observations of old B1, B2, and B3 frequencies were selected for the BeiDou-3 satellite POD in this study.

China is developing the International GNSS Monitoring and Assessment Service (iGMAS) to monitor the nation's BeiDou satellites and other global navigation satellites to ensure the precise-orbit products of the systems in order to improve the signal availability, reliability, precision, and accuracy. The iGMAS consists of three operational Data Centers (DCs), 12 Analysis Centers (ACs), 18 Tracking Stations (eight domestic, eight overseas, one in the North Pole, and one in the South Pole), one Monitoring and Analysis Center, one Operation Control and Management Center, and one Analysis Center Coordinator. The three DCs are located in Wuhan University, National University of Defense Technology, and the National Time Service Center. The twelve ACs are located in the Institute of Geodesy and Geophysics (IGG), Wuhan University (WHU), Shanghai Astronomical Observatory (SHA), Xi'an Satellite Control Center (XSC), Chang'an University (CHD), Beijing Space Information Relay and Transmission Technology Research Center (TAC), Chinese Academy of Surveying and Mapping (CGS), The PLA Information Engineering University (LSN), Xi'an Research Institute of Surveying and Mapping (XRS), China University of Mining and Technology (CUM), Beijing Aerospace Control Center (BAC), and the National Time Service Center (NTS). The Monitoring and Analysis Center is located in $\mathrm{Xi}^{\prime}$ an Research Institute of Surveying and Mapping. The Operation Control and Management Center and Analysis Center Coordinator are located in Beijing. A continuous tracking network for BeiDou and other GNSS satellites for scientific and engineering applications has been deployed by iGMAS. By August 2016, there are nine iGMAS stations that can track the BeiDou-3 satellites, each with B1 and B3 observations. The Multi-GNSS Experiment (MGEX) was established by the International GNSS Service (IGS) to track, collate, and analyze all available GNSS signals, which include signals from the BeiDou, Galileo, Quasi-Zenith Satellite System (QZSS), Navigation with Indian Constellation/IRNSS (NAVIC) systems, modernized GPS and GLONASS satellites, and any space-based augmentation system (SBAS) of interest. There are only four MGEX stations, roap, stj3, tlsg, and yel2 that can track the BeiDou-3 satellites, although each currently has only B1 observations. 
In this study, 9 iGMAS stations (cf. Figure 1) were selected for the BeiDou-3 satellite POD, and the station information is listed in Table 2. For comparison, 52 MGEX stations (cf. Figure 1) were selected for BeiDou-2 satellites POD. The observation data of iGMAS and MGEX from 16 July to 14 August 2016 were processed for BeiDou-3 and BeiDou-2 satellite precise-orbit determination, respectively.

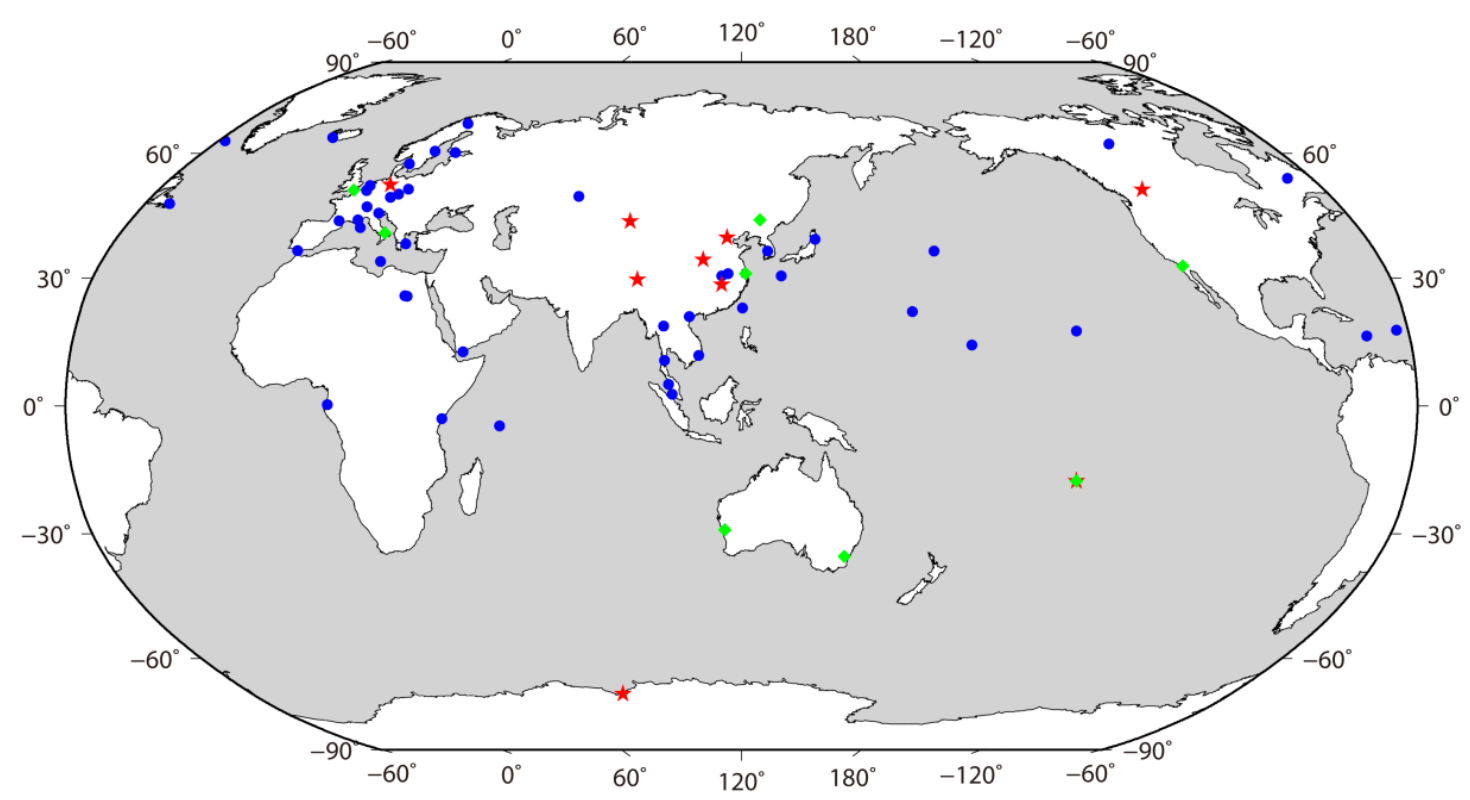

Figure 1. Tracking stations in precise-orbit determination and satellite laser ranging (SLR) validation for BeiDou-2 and BeiDou-3 satellites. The stations are represented by red five-pointed stars, blue circles, and green diamonds for iGMAS, Multi-GNSS Experiment (MGEX), and SLR stations, respectively.

Table 2. Selected tracking stations from the International GNSS (Global Navigation Satellite System) Monitoring and Assessment Service (iGMAS).

\begin{tabular}{ccccc}
\hline Station Abb. & Location & Country & Receiver & Antenna \\
\hline BJF1 & Beijing & China & CETC-54 GMR-4011 & LEIAR25.R4 LEIT \\
BRCH & Braunschweig & Germany & CETC-54 GMR-4011 & LEIAR25.R4 LEIT \\
CLGY & Calgary & Canada & CETC-54 GMR-4011 & LEIAR25.R4 LEIT \\
GUA1 & Urumqi & China & GNSS_GGR & RINT-8CH CETD \\
LHA1 & Lhasa & China & CETC-54 GMR-4011 & NOV750.R4 NOVS \\
TAHT & Tahiti & France & GNSS_GGR & RINT-8CH CETD \\
WUH1 & Wuhan & China & CETC-54 GMR-4011 & LEIAR25.R4 LEIT \\
XIA1 & Xian & China & GNSS_GGR & RINT-8CH CETD \\
XHON & Antarctica & United Nations & CETC-54 GMR-4011 & LEIAR25.R4 LEIT \\
\hline
\end{tabular}

\section{Methods and Strategies for BeiDou-3 and BeiDou-2 Satellite POD}

The routine software package developed by the Analysis Centre at the Institute of Geodesy and Geophysics, Chinese Academy of Sciences has been used to process data for BeiDou-3 and BeiDou-2 satellites in this study. A two-step method is adopted in this study. In the first step, the stations for BeiDou-3 and BeiDou-2 satellite POD are embodied in a GPS POD process using the ionosphere-free linear combination (LC) of L1 and L2 phase observations with IGS rapid products. Then, in the second step, the relative accurate station coordinates (CRDs), earth rotation parameters (ERPs), and zenith tropospheric delays (ZTDs), which were obtained from the GPS POD process, are further fixed in the BeiDou-3 and BeiDou-2 satellite POD process using the ionosphere-free linear combination (LC) of B1 and B3 phase and code observations beginning with the broadcast ephemeris. In the second step, only BeiDou-3- and BeiDou-2-related parameters (i.e., six keplerian elements and five solar radiation parameters (Constants in the D-, Y-, and X-directions and periodic in the 
X-direction), and pseudo-stochastic orbit parameters are estimated). The BeiDou-3 satellite antenna phase center (PCO) values are provided by the Operation Control Department, and no phase center variation (PCV) values are available. The estimated PCO and PCV for BDS IGSO and MEO satellites by Dilssner et al. [18] are used for BeiDou-2 satellites. However, the PCO and PCV for ground antennas are not available. Important aspects of the selected processing strategy regarding the observation model and force model are listed in Table $3[19,20]$.

Table 3. Summary of the precise-orbit determination strategy for BeiDou-3 satellites. ERPs, earth rotation parameters; POD, precise orbit determination; $\mathrm{PCO}$, satellite antenna phase center; PCV, phase center variation, ZTDs, zenith tropospheric delays.

\begin{tabular}{|c|c|}
\hline Strategy & Describe \\
\hline Observations & $\begin{array}{l}\text { Double-differenced ionosphere-free code, and phase combination of B1 and } \\
\text { B3 in deployment phase } 1\end{array}$ \\
\hline Elevation angle cut-off & $7^{\circ}$ \\
\hline Sampling rate & $30 \mathrm{~s}$ \\
\hline Data span & Three days \\
\hline Station coordinates and ERPs & Fixed using estimates from the GPS daily POD process \\
\hline Weighting & $\begin{array}{c}4 \mathrm{~mm} \text { for phase observations, } 2 \mathrm{~m} \text { for code observations and } \\
\text { elevation-dependent weighting }\end{array}$ \\
\hline Satellite antenna PCO and PCV & $\begin{array}{c}\text { BeiDou-3: PCO values are given by the Operation Control Department } \\
\text { (with authorization), no PCV applied } \\
\text { BeiDou-2: Obtained from Dilssner et al. [18] }\end{array}$ \\
\hline SLR retro-reflector offsets & $\begin{array}{c}\text { BeiDou-3: Given by the Operation Control Department (with authorization) } \\
\text { BeiDou-2: Obtained from ILRS }\end{array}$ \\
\hline Attitude model & $\begin{array}{l}\text { BeiDou-3: Yaw-steering attitude mode } \\
\text { BeiDou-2: Yaw-steering and orbit normal attitude mode }\end{array}$ \\
\hline Ground antenna PCO and PCV & Not applied \\
\hline Troposphere & $\begin{array}{l}\text { Dry and wet GMF mapping functions; ZTDs estimated for each station at } \\
\text { intervals of two hours; GPS daily ZTDs used as a priori values }\end{array}$ \\
\hline Precession and nutation & IAU 2010 precession and IAU 2010 nutation model \\
\hline Geopotential & EGM2008 $12 \times 12$ \\
\hline $\begin{array}{l}\text { Solid Earth tides, ocean tides and } \\
\text { solid Earth pole tides }\end{array}$ & IERS Conventions 2010 \\
\hline N body & JPL DE405 ephemeris \\
\hline Orbital parameters & $\begin{array}{l}\text { Six orbit elements and five ECOM SRP parameters were estimated: } \\
\text { constants in the } \mathrm{D}, \mathrm{Y} \text { and } \mathrm{X} \text { directions; periodic terms in the } \mathrm{X} \text { direction }\end{array}$ \\
\hline Pseudo-stochastic orbit parameters & $\begin{array}{l}\text { Every } 12 \mathrm{~h} \text {; constrained to } 1 \times 10^{-6} \mathrm{~m} / \mathrm{s} \text { in the radial direction, } 1 \times 10^{-5} \mathrm{~m} / \mathrm{s} \\
\text { in the along direction, and } 1 \times 10^{-8} \mathrm{~m} / \mathrm{s} \text { in the cross-track direction }\end{array}$ \\
\hline Ambiguity & Real constant value for each ambiguity arc \\
\hline
\end{tabular}

\section{Results}

The obtained BeiDou-3 and BeiDou-2 satellite orbits in this study are assessed in terms of both internal consistency and external validation. For internal consistency, overlap comparisons are conducted. For external validation, satellite laser ranging (SLR) observations are used to independently assess the accuracy of the BeiDou-3 satellite orbits.

\subsection{Overlap Comparison}

For any two adjacent three-day arc solutions shifted by one day, there are 48-h overlap orbits. The last observed day and first middle day of the adjacent solution are compared in this study. Figure 2 shows the overlap comparison algorithm for adjacent orbit solutions of a three-day arc. 


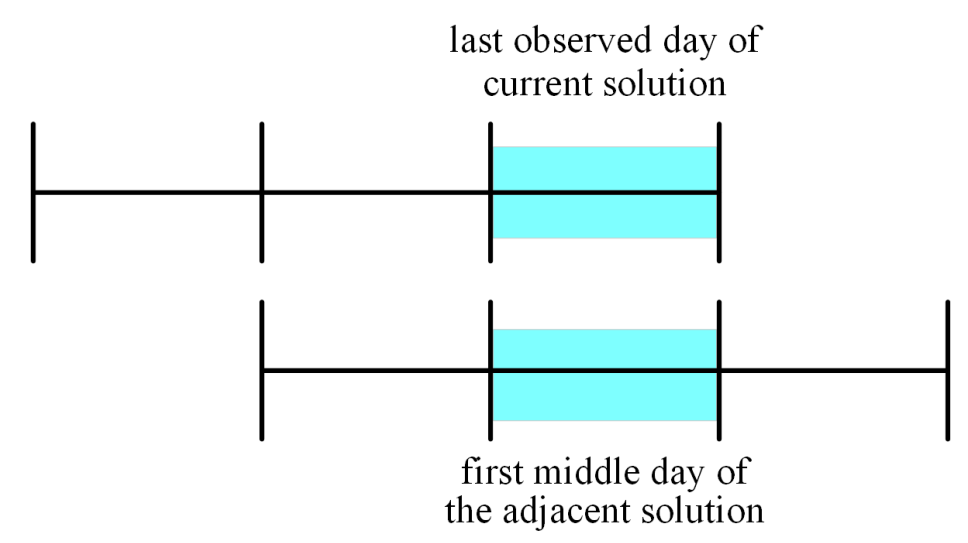

Figure 2. Overlap comparison of BeiDou-3 and BeiDou-2 orbit determination.

The average daily root mean square (RMS) values of the 24-h overlap in the radial, along, and cross-track components for each satellite are shown in Table 4 and Figures 3-7. The RMS values for the along component for all BeiDou satellites are the largest among the three components, whereas the radial component has the smallest RMS values. Furthermore, BeiDou-3 MEO satellites (C33 and C34) have larger RMS values than the BeiDou-3 IGSO satellites (C31 and C32), whereas BeiDou-2 MEO satellites have smaller RMS values than the BeiDou-2 IGSO satellites. Furthermore, BeiDou-3 IGSO and BeiDou-2 IGSO satellites have identical RMS values, whereas BeiDou-3 MEO satellites have larger RMS values than the BeiDou-2 MEO satellites. In addition, BeiDou-2 GEO satellites yield significantly large RMS values among all of the BeiDou-2 satellites. BeiDou-3 MEO satellites have inferior POD accuracy compared with BeiDou-2 MEO satellites because the existing tracking network for BeiDou-3 MEO satellites is not well distributed worldwide, which implies that the tracking network does not have a good coverage for global MEO satellites, whereas the regional IGSO satellites are relatively better observed. In addition, the RMS residuals are approximately $10 \mathrm{~cm}$ and $25 \mathrm{~cm}$ in the radial and along components for BeiDou-3 IGSO satellites, respectively. For BeiDou-3 MEO satellites, the RMS residuals are approximately $40 \mathrm{~cm}$ and $60 \mathrm{~cm}$ in the radial and along components, respectively. The RMS residuals are approximately $10 \mathrm{~cm}$ and $20 \mathrm{~cm}$ in the radial and along components for BeiDou-2 IGSO satellites, respectively. For BeiDou-2 MEO satellites, the RMS residuals are approximately $5 \mathrm{~cm}$ and $15 \mathrm{~cm}$ in the radial and along components, respectively.

Table 4. Averaged daily root mean square (RMS) values of 24-h orbit overlap comparison.

\begin{tabular}{cccc}
\hline PRN of BeiDou Satellites & Radial $(\mathbf{c m})$ & Along(cm) & Cross-track $(\mathbf{c m})$ \\
\hline BeiDou-3 C31 (IGSO) & 12.51 & 24.95 & 23.82 \\
BeiDou-3 C32 (IGSO) & 11.88 & 25.81 & 24.32 \\
BeiDou-3 C33 (MEO) & 40.75 & 58.67 & 51.82 \\
BeiDou-3 C34 (MEO) & 41.16 & 59.88 & 59.11 \\
BeiDou-2 C01 (GEO) & 27.39 & 58.72 & 36.49 \\
BeiDou-2 C02 (GEO) & 25.72 & 38.79 & 29.09 \\
BeiDou-2 C03 (GEO) & 27.32 & 30.87 & 36.78 \\
BeiDou-2 C04 (GEO) & 41.55 & 69.19 & 47.12 \\
BeiDou-2 C05 (GEO) & 33.58 & 41.25 & 34.81 \\
BeiDou-2 C06 (IGSO) & 12.35 & 20.05 & 10.77 \\
BeiDou-2 C07 (IGSO) & 11.46 & 16.12 & 10.57 \\
BeiDou-2 C08 (IGSO) & 8.49 & 20.71 & 15.03 \\
BeiDou-2 C09 (IGSO) & 11.12 & 16.67 & 13.17 \\
BeiDou-2 C10 (IGSO) & 11.23 & 20.65 & 14.65 \\
BeiDou-2 C15 (IGSO) & 9.26 & 15.63 & 12.21 \\
BeiDou-2 C11 (MEO) & 5.69 & 12.45 & 6.37 \\
BeiDou-2 C12 (MEO) & 4.46 & 13.46 & 7.31 \\
BeiDou-2 C14 (MEO) & 5.22 & 14.41 & 12.19 \\
\hline
\end{tabular}




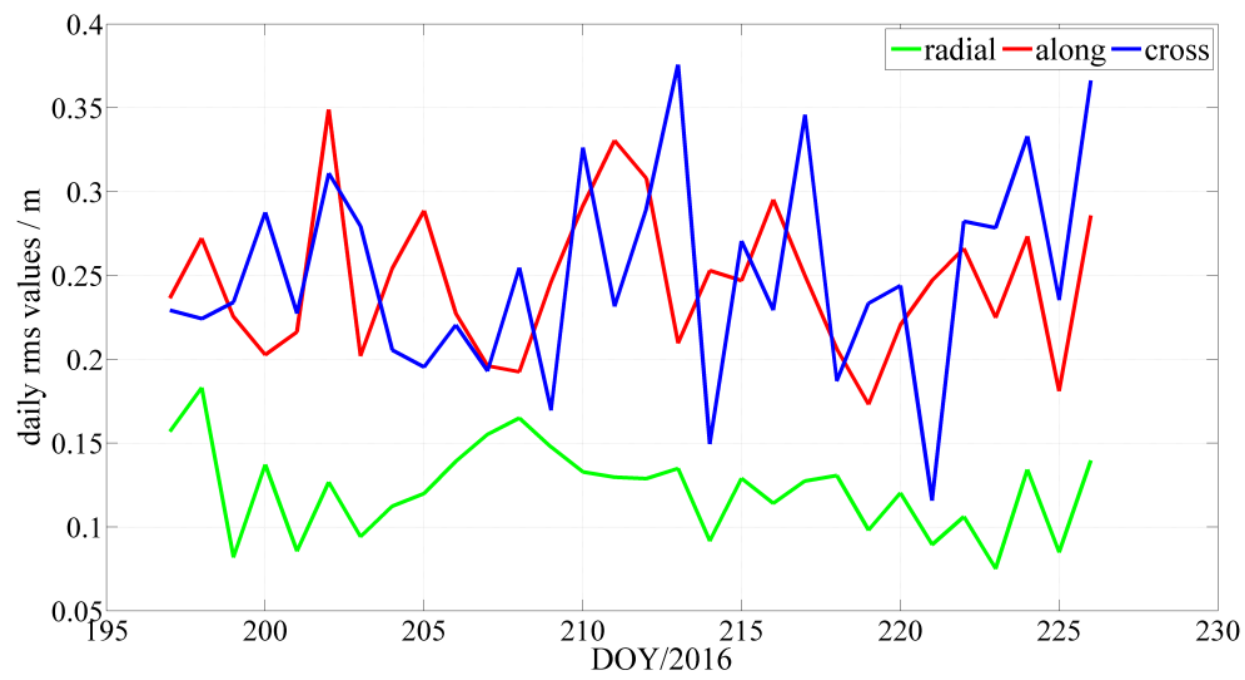

Figure 3. BeiDou C31 satellite overlap comparison in the radial, along, and cross-track components.

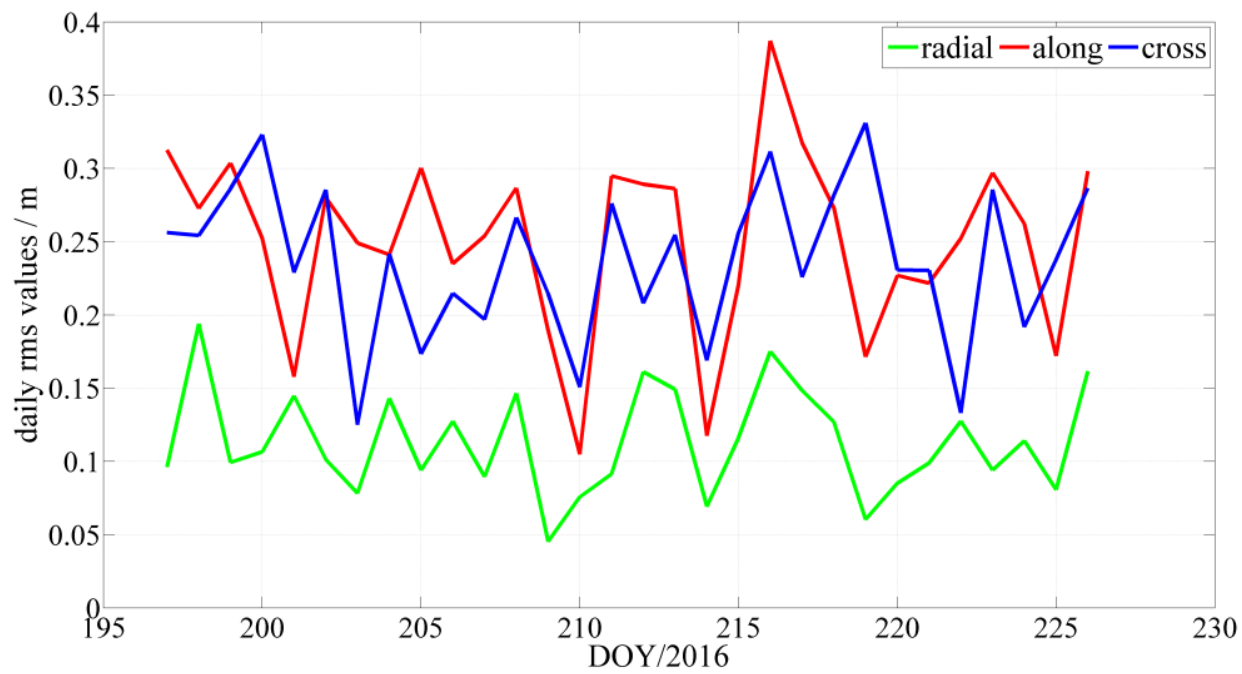

Figure 4. BeiDou C32 satellite overlap comparison in the radial, along, and cross-track components.

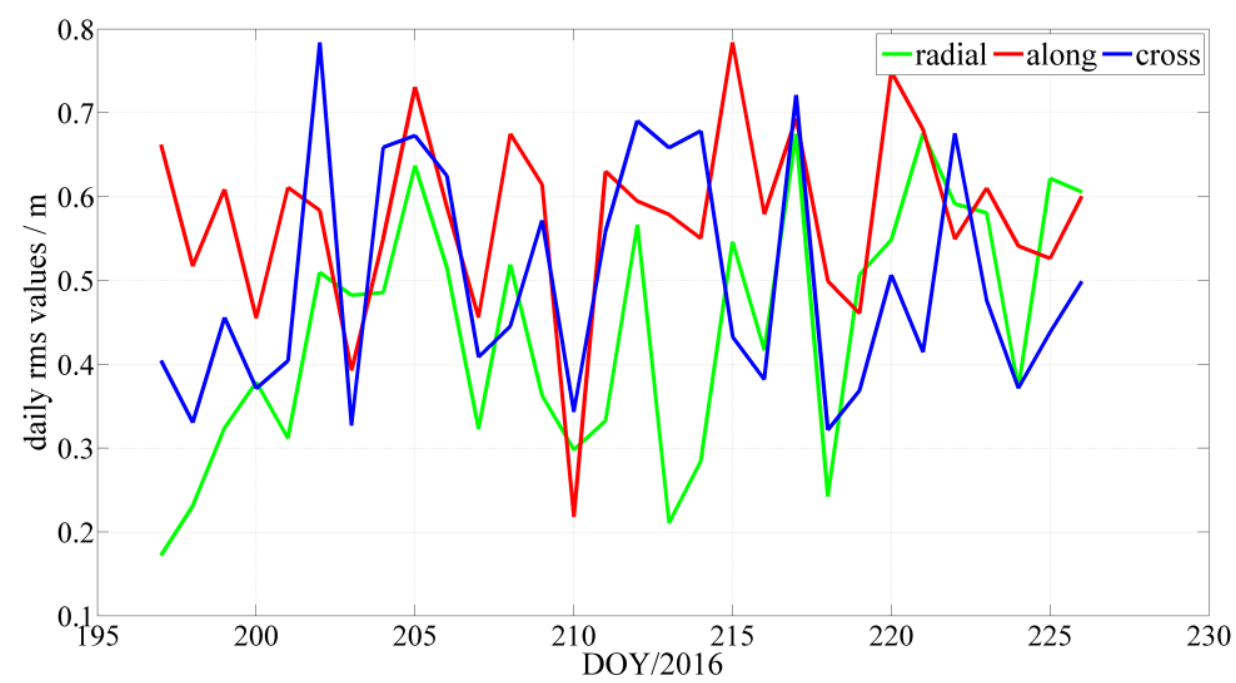

Figure 5. BeiDou C33 satellite overlap comparison in the radial, along, and cross-track components. 


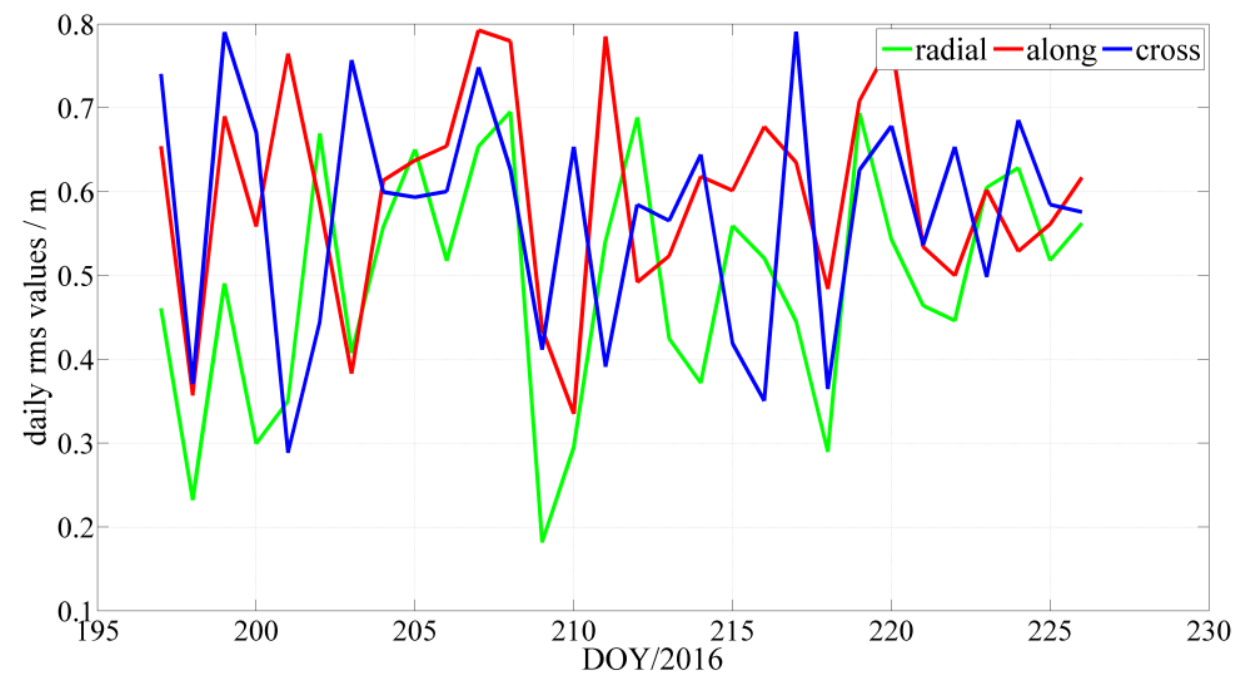

Figure 6. BeiDou C34 satellite overlap comparison in the radial, along, and cross-track components.

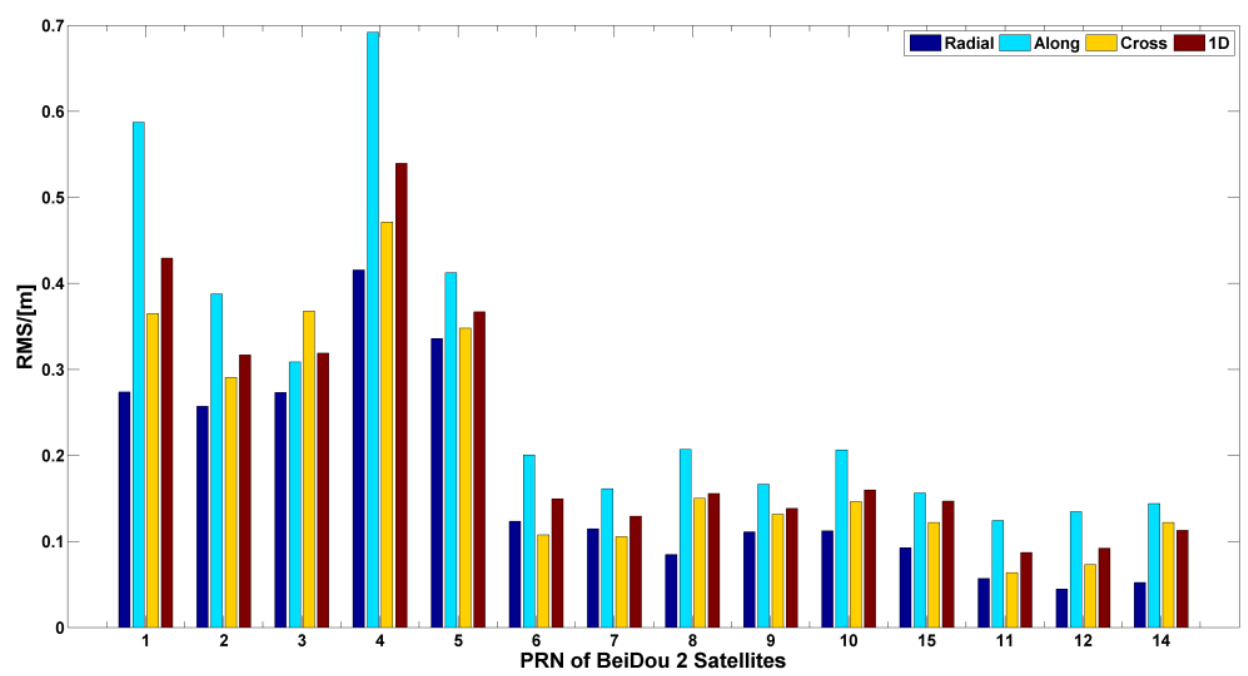

Figure 7. BeiDou-2 satellite overlap comparison in the radial, along, and cross-track components.

\subsection{SLR Validation}

SLR is a powerful and independent technique that enables the independent validation of satellite orbits [21,22]. The difference between the observed SLR values and the computed distances using BeiDou satellite orbits and SLR reference station coordinates can be used to identify whether there are systematic biases or unexpected errors in the estimated BeiDou satellite orbits.

All BeiDou-3 satellites and some BeiDou-2 satellites are monitored by the International Laser Ranging Service (ILRS) SLR tracking stations. The SLR range observations can be accessed via the File Transfer Protocol (FTP) services provided by the ILRS. For this study, the latest SLR station coordinates and system eccentricities were obtained from the ILRS. The retro-reflector offsets of BeiDou-3 satellites were provided by the Operation Control Department, and those of the BeiDou-2 satellites were obtained from ILRS. There were 12, 29, 45, 10, 114, 36, 12,5 and 104 normal points (NP) available for satellites C31, C32, C33, C34, C01, C08, C10, and C11, respectively, during the study period. These NPs were from the Yarragadee, Monument Peak, Papeete, Changchun, Shanghai, Mount Stromlo, Herstmonceux, and Matera stations (cf. Figure 7). The SLR observations were corrected using the retro-reflector offsets. The mean and RMS of SLR residuals of the middle day for orbit solutions are summarized in Table 5 and illustrated in Figures 8-15. The result is generally consistent with the 
overlap comparison in the radial direction in the orbit determination. The overall RMS values for BeiDou-3 IGSO and MEO are approximately $11 \mathrm{~cm}$ and $40 \mathrm{~cm}$, respectively. The overall RMS values for BeiDou-2 IGSO and MEO are approximately $10 \mathrm{~cm}$ and $6 \mathrm{~cm}$, respectively. Table 5 illustrates that the mean offsets for BeiDou-3 IGSO and MEO are $-4 \mathrm{~cm}$ and $15 \mathrm{~cm}$, respectively. Table 5 also shows that the mean offsets for BeiDou-2 IGSO and MEO are $-4 \mathrm{~cm}$ and $3 \mathrm{~cm}$, respectively. Further, BeiDou-3 MEO satellites have slightly larger overall RMS values and mean offsets than the BeiDou-3 IGSO satellites, whereas BeiDou-2 MEO satellites have slightly smaller overall RMS values and mean offsets than the BeiDou-2 IGSO satellites. In addition, BeiDou-2 GEO satellites yield significantly larger RMS of SLR residuals compared to other BeiDou-2 satellites.

Table 5. SLR residuals of BeiDou-3 satellites.

\begin{tabular}{ccc}
\hline PRN of BeiDou Satellites & Mean $(\mathbf{c m})$ & RMS $(\mathbf{c m})$ \\
\hline BeiDou-3 C31 (IGSO) & -3.82 & 11.25 \\
BeiDou-3 C32 (IGSO) & -3.51 & 11.28 \\
BeiDou-3 C33 (MEO) & 15.64 & 38.61 \\
BeiDou-3 C34 (MEO) & 15.44 & 40.26 \\
BeiDou-2 C01 (GEO) & -2.68 & 27.98 \\
BeiDou-2 C08 (IGSO) & -4.27 & 8.51 \\
BeiDou-2 C10 (IGSO) & -4.97 & 10.32 \\
BeiDou-2 C11 (MEO) & 2.92 & 5.91 \\
\hline
\end{tabular}

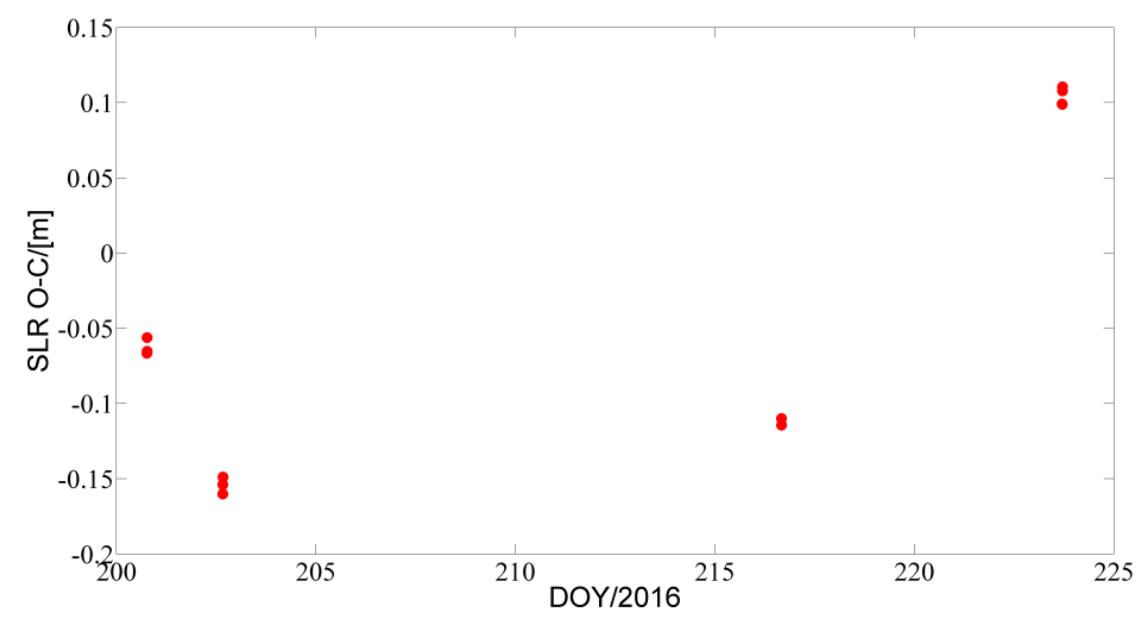

Figure 8. SLR validation for BeiDou-3 C31 satellite.

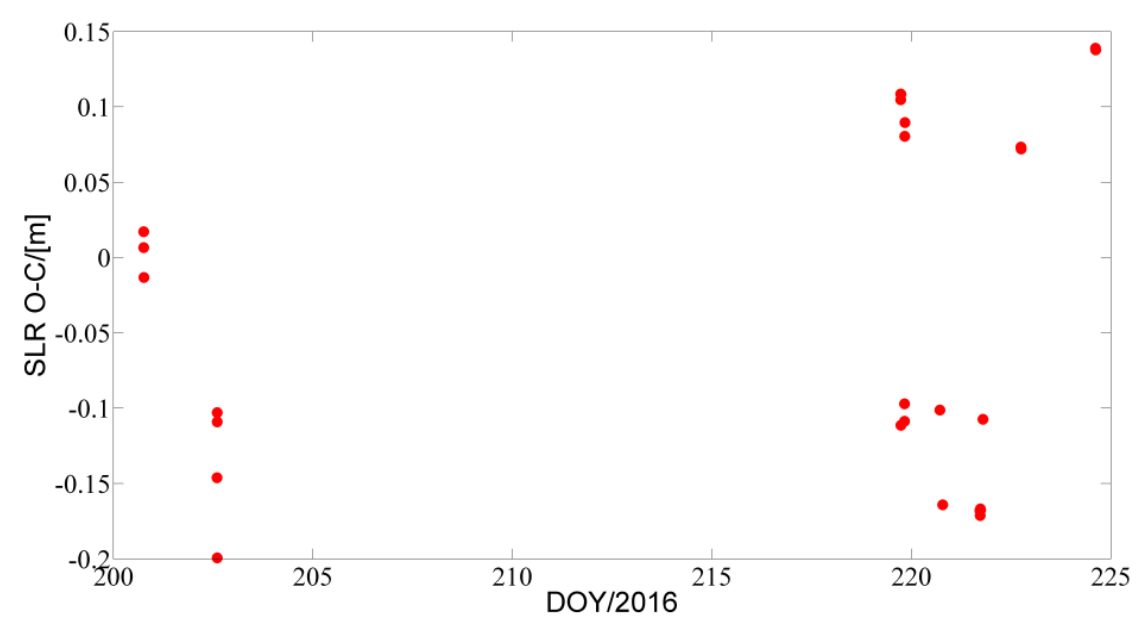

Figure 9. SLR validation for BeiDou-3 C32 satellite. 


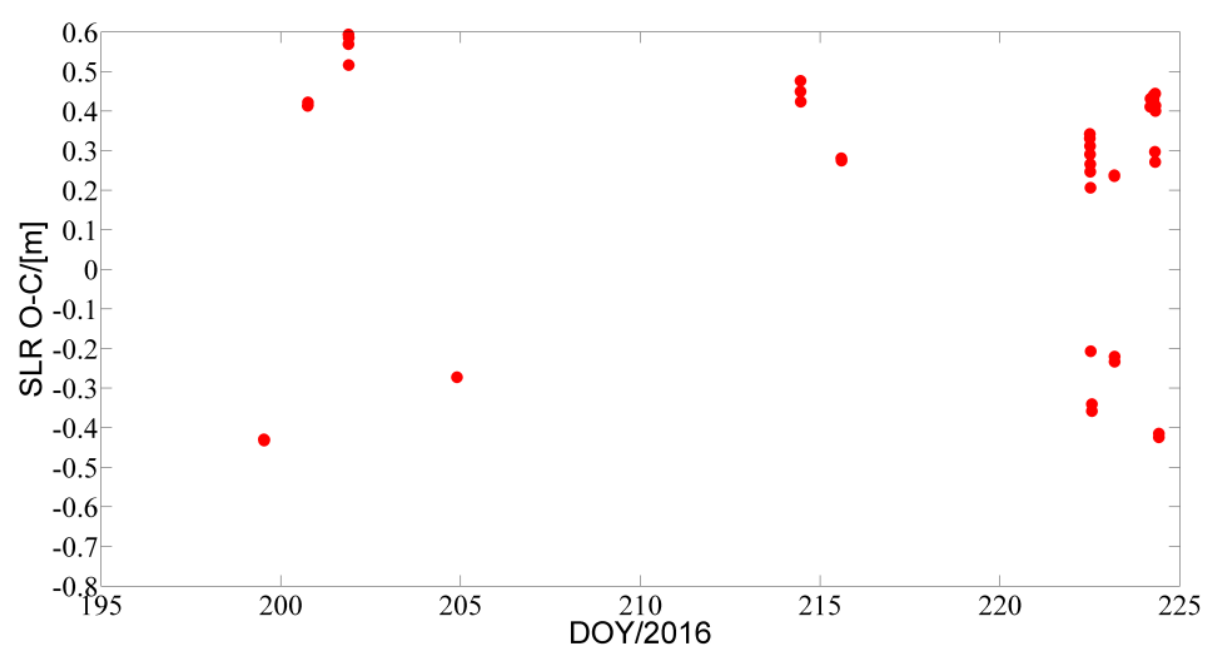

Figure 10. SLR validation for BeiDou-3 C33 satellite.

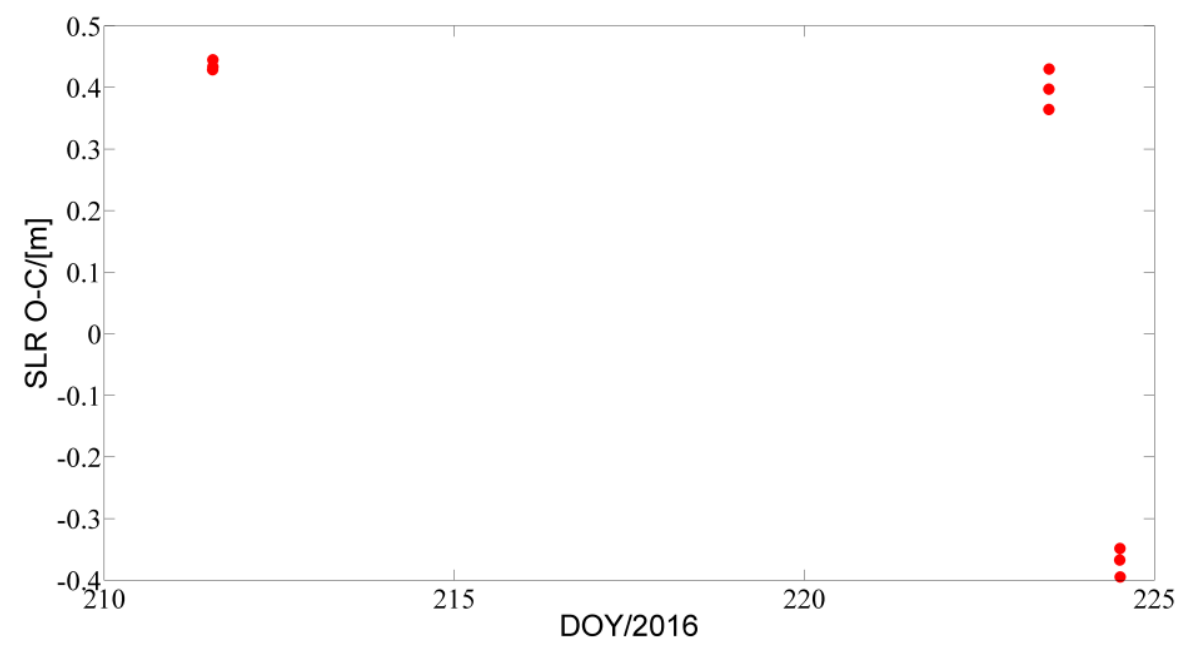

Figure 11. SLR validation for BeiDou-3 C34 satellite.

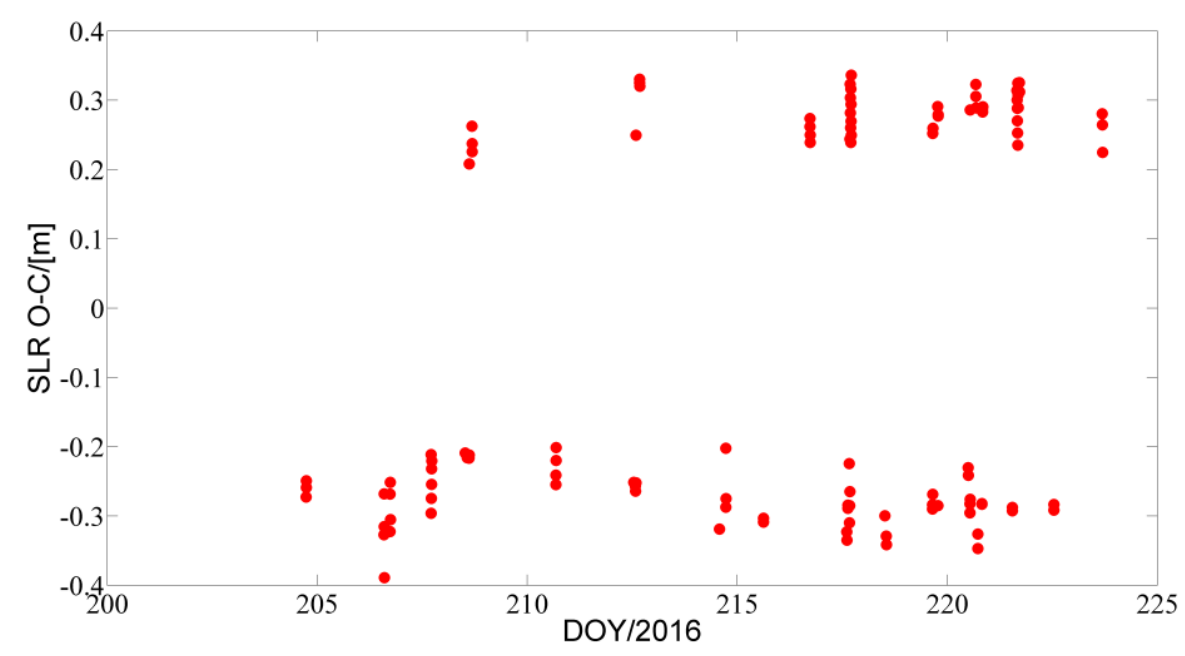

Figure 12. SLR validation for BeiDou-2 C01 satellite. 


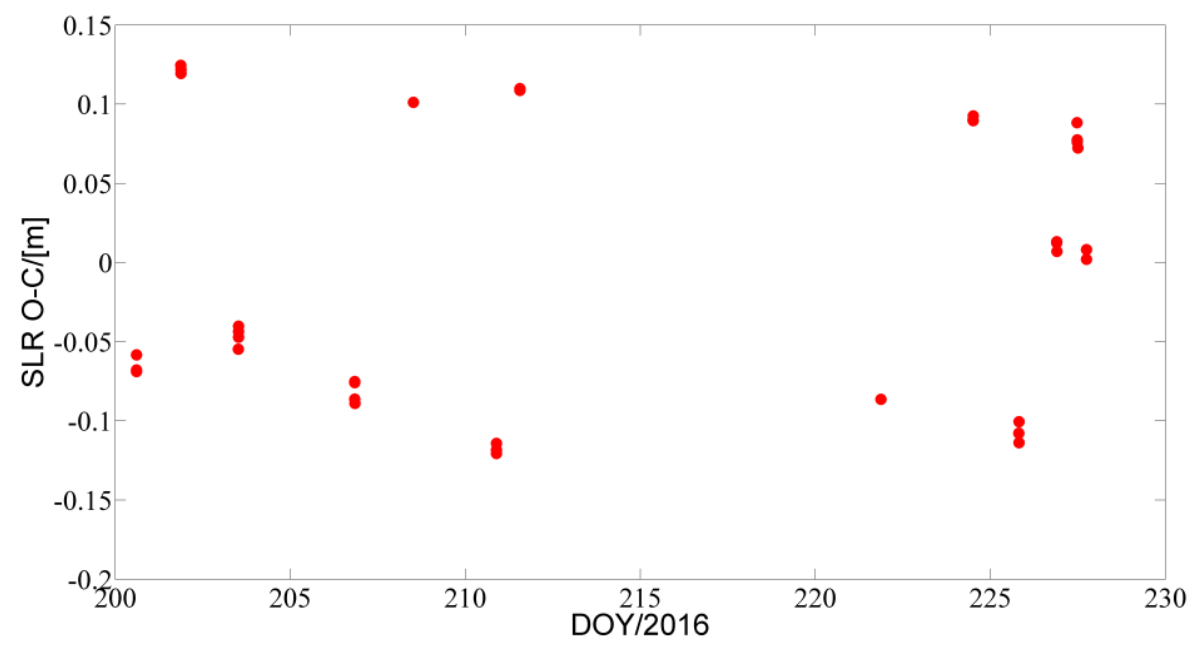

Figure 13. SLR validation for BeiDou-2 C08 satellite.

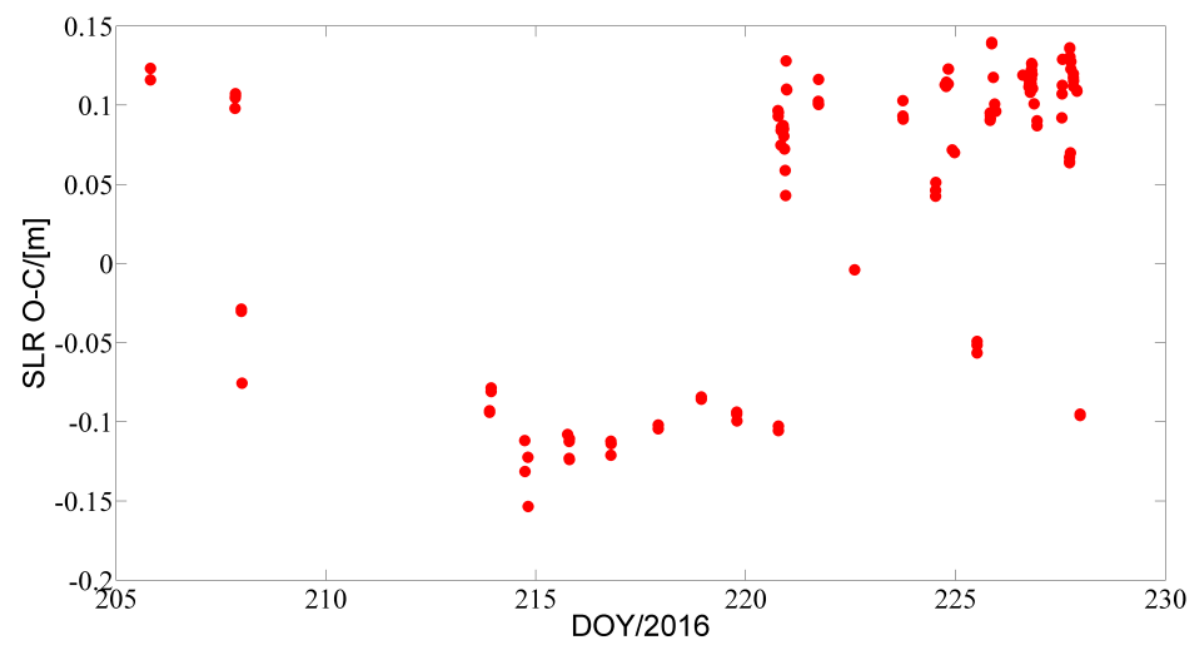

Figure 14. SLR validation for BeiDou-2 C10 satellite.

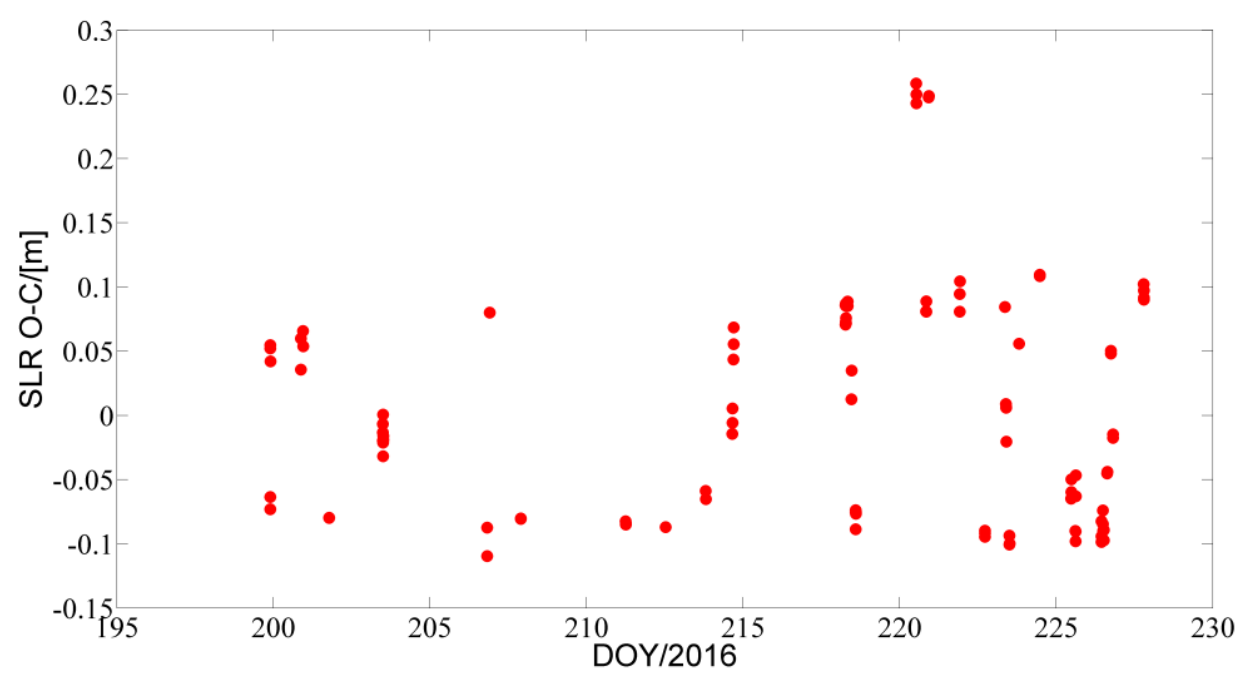

Figure 15. SLR validation for BeiDou-2 C11 satellite. 


\section{Conclusions and Discussion}

We processed one month of observations from a very limited number of nine stations in the iGMAS tracking network for the precise orbit determination of BeiDou-3 satellites. For comparison, the observations from 52 MGEX stations were processed for the precise orbit determination of BeiDou-2 satellites. A two-step method was implemented in the routine software package developed by the Analysis Centre at the Institute of Geodesy and Geophysics, Chinese Academy of Sciences. Internal consistency and SLR validations were conducted, and the orbit radial component can reach an accuracy on the level of 1 decimeter and 4 decimeters for BeiDou-3 IGSO and MEO, respectively. The orbit radial component can reach an accuracy on the level of 1 decimeter and 0.5 decimeters for BeiDou-2 IGSO and MEO, respectively.

At present, the orbit determination performance for BeiDou-3 satellites, particularly for global BeiDou-3 MEO satellites, remains inferior to that of BeiDou-2 satellites and other GNSS constellations such as GPS and GLONASS. This problem has been attributed to the lack of a well-distributed worldwide tracking network for BeiDou-3 satellites, particularly MEO satellites. Further efforts may involve two aspects: deployment of a larger global tracking network for BeiDou-3 satellites and more accurate dynamic models for BeiDou-3 satellites.

For BeiDou-3 satellites, a relatively small number of ground tracking stations were deployed. With a larger and more well-distributed global tracking network, which can provide better coverage for all BeiDou-3 satellites, particularly for global MEO satellites, the accuracy of BeiDou-3 satellite POD will be improved. Meanwhile, more ground tracking stations and precise-orbit products will be notably helpful with the SRP modeling for BeiDou-3 satellites in the near future [23].

Acknowledgments: This work was supported by National key Research Program of China "Collaborative Precision Positioning Project" (No. 2016YFB0501900), the National Nature Science Foundation of China (Grant No. 41231064, 41674022, 41304034, and 41574033). We also acknowledge the funding support of the State Key Laboratory of Geodesy and Earth's Dynamics (Institute of Geodesy and Geophysics, CAS) (No. SKLGED2014-3-1-E). The authors would like to extend their sincere gratitude to iGMAS for providing the observation data. The authors are thankful to the ILRS for providing the BeiDou satellite SLR observation data. The authors are grateful to the IGS Multi-GNSS Experiment (http://mgex.igs.org) for supplying the related information about the BeiDou Navigation Satellite System.

Author Contributions: Bingfeng Tan and Yunbin Yuan provided the initial idea for this study. Bingfeng Tan and Yafei Ning conceived and designed the POD experiments. Bingfeng Tan and Xifeng Liu analyzed the experiment results. Bingfeng Tan and Mingyue Wen wrote the paper.

Conflicts of Interest: The authors declare no conflict of interest.

\section{References}

1. Yang, Y. Progress, contribution and challenges of compass/BeiDou satellite navigation system. Acta Geod. Cartogr. Sin. 2010, 39, 1-6.

2. The Multi-GNSS Experiment and Pilot Project (MGEX). Available online: http://igs.Org/mgex/status-bds (accessed on 17 October 2016).

3. Zhang, B.; Teunissen, P.J.; Odijk, D. A novel un-differenced PPP-RTK concept. J. Navig. 2011, 64, 180-191. [CrossRef]

4. Zhang, B.; Yuan, Y.; Chai, Y. QIF-based GPS long-baseline ambiguity resolution with the aid of atmospheric delays determined by PPP. J. Navig. 2016, 69, 1-15. [CrossRef]

5. Ning, Y.; Yuan, Y.; Chai, Y.; Huang, Y. Analysis of the bias on the BeiDou geo multipath combinations. Sensors 2016. [CrossRef] [PubMed]

6. Zhang, H.; Yuan, Y.; Li, W.; Li, Y.; Chai, Y. Assessment of three tropospheric delay models (IGGtrop, EGNOS and UNB3m) based on precise point positioning in the Chinese region. Sensors 2016. [CrossRef] [PubMed]

7. Chen, J.; Hu, X.; Tang, C.; Zhou, S.; Guo, R.; Pan, J.; Li, R.; Zhu, L. Orbit Determination and Time Synchronization for New-Generation BeiDou Satellites: Preliminary Results; Science China Press: Beijing, China, 2016. (In Chinese) 
8. Chen, Y.; Hu, X.; Zhou, S.; Song, X.; Huang, Y.; Mao, Y.; Huang, C.; Chang, Z.; Wu, S. A new autonomous orbit determination algorithm based on inter-satellite ranging measurements. Sci. Sin-Phys. Mech. Astron. 2015. [CrossRef]

9. Mao, Y.; Hu, X.; Song, X.; Chen, Y.; Jia, X.; Wu, X. Satellite autonomous navigation algorithm analysis based on broadcast ephemeris parameters. Sci. Sin-Phys. Mech. Astron. 2015. [CrossRef]

10. Yang, W.; Gong, H.; Hu, X.; Wei, S.; Guo, W. 2-GEO TWSTFT for BDS ground stations: Confidence interval of clock difference Allan variance. Sci. Sin-Phys. Mech. Astron. 2015. [CrossRef]

11. Zhou, S.; Hu, X.; Liu, L.; Guo, R.; Zhu, L.; Chang, Z.; Tang, C.; Gong, X.; Li, R.; Yu, Y. Applications of two-way satellite time and frequency transfer in the BeiDou navigation satellite system. Sci. Sin-Phys. Mech. Astron. 2016. [CrossRef]

12. Ge, M.; Zhang, H.P.; Jia, X.L.; Song, S.L.; Wickert, J. What is achievable with the current compass constellation. GPS World 2012, 1, 29-34.

13. Montenbruck, O.; Hauschild, A.; Steigenberger, P.; Hugentobler, U.; Teunissen, P.; Nakamura, S. Initial assessment of the compass/BeiDou-2 regional navigation satellite system. GPS Solut. 2013, 17, 211-222. [CrossRef]

14. Steigenberger, P.; Hugentobler, U.; Hauschild, A.; Montenbruck, O. Orbit and clock analysis of compass geo and IGSO satellites. J. Geod. 2013, 87, 515-525. [CrossRef]

15. Zhao, Q.; Guo, J.; Li, M.; Qu, L.; Hu, Z.; Shi, C.; Liu, J. Initial results of precise orbit and clock determination for compass navigation satellite system. J. Geod. 2013, 87, 475-486. [CrossRef]

16. Lou, Y.; Liu, Y.; Shi, C.; Yao, X.; Zheng, F. Precise orbit determination of BeiDou constellation based on bets and MGEX network. Sci. Rep. 2014. [CrossRef] [PubMed]

17. CNSS (Compass/BeiDou Navigation Satellite System)/BDS (BeiDou Navigation System). Available online: https://directory.Eoportal.Org/web/eoportal/satellite-missions/c-missions/cnss (accessed on 17 October 2016).

18. Dilssner, F.; Springer, T.; Schönemann, E.; Enderle, W. Estimation of satellite antenna phase center corrections for BeiDou. In Proceedings of the IGS workshop 2014, Pasadena, CA, USA, 23-27 June 2014.

19. Beutler, G.; Jäggi, A.; Hugentobler, U.; Mervart, L. Efficient satellite orbit modelling using pseudo-stochastic parameters. J. Geod. 2006, 80, 353-372. [CrossRef]

20. Dach, R.; Hugentobler, U.; Fridez, P.; Meindl, M. Bernese GPS Software, Version 5.0; Astronomical Institute, University of Bern: Bern, Switzerland, 2007.

21. Montenbruck, O.; Steigenberger, P.; Kirchner, G. GNSS satellite orbit validation using satellite laser ranging. In Proceedings of the ILRS Workshop 2013, Fujiyoshida, Japan, 9-14 October 2013.

22. Pearlman, M.R.; Degnan, J.J.; Bosworth, J.M. The international laser ranging service. Adv. Space Res. 2002, 30, 135-143. [CrossRef]

23. Tan, B.; Yuan, Y.; Zhang, B.; Hsu, H.Z.; Ou, J. A new analytical solar radiation pressure model for current beidou satellites: IGGBSPM. Sci. Rep. 2016. [CrossRef] [PubMed]

(C) 2016 by the authors; licensee MDPI, Basel, Switzerland. This article is an open access article distributed under the terms and conditions of the Creative Commons Attribution (CC-BY) license (http://creativecommons.org/licenses/by/4.0/). 